\title{
Public-private partnership (PPP): legal regulation, techniques and practice in the context of industrialization
}

\author{
Oksana Trotsenko ${ }^{1 *}$, Oleksandr Batanov $^{2}$ and Natalia Simachkova ${ }^{1}$ \\ ${ }^{1}$ Ural State University of Economics, 8 Marta Str., 62, 620144 Ekaterinburg, Russia \\ ${ }^{2}$ Koretsky Institute of State and Law, National Academy of Sciences of Ukraine, Tryokhsviatitelska \\ str., 4, Kyiv, 01601 Ukraine
}

\begin{abstract}
In the article, public-private partnership (hereinafter - PPP) is analyzed as one of the ways to implement infrastructure projects. This form of cooperation arises primarily in those areas for which the state bears responsibility (for ex-ample, road construction, housing and communal services, healthcare, con-struction of social infrastructure facilities, etc.). Due to the strategic importance of the above spheres of the economy, the state can not completely abandon control over their functioning. At the same time, there is a need to maintain the operability of the objects included in them, as well as to attract additional (in addition to budget) funding. Based on foreign experience, the most optimal form of cooperation in this case is PPP.
\end{abstract}

\section{Introduction}

Public-private partnership have become popular with governments and the European Union as a way of providing public infrastructure and public services. There are a number of reasons.

1. Private sector will do a better and less bureaucratic job.

2. Reducing the burden on the public sector budgets.

3. PPP is a contract made with a public body - a set of terms regulate the provision of services by the private sector and the money provided by both to a design made by the public body.

4. PPP brings public and private sectors together in long-term partnership for mutual benefit.

One of the sense that the private sector will do a better and less bureaucratic job. Another is that private sector is used to paying attention to cost and the provision of private finance will reduce the need for the taxpayer to pay the cost in a period when public sector budgets need to be kept in check. So, the fact that PPPs continue to spread around the world (for example, in states such as the Indian state of West Bengal or the People's republic of

\footnotetext{
${ }^{*}$ Corresponding author: trocenko.o@mail.ru
} 
Vietnam) and into new sectors (for example health and education) suggests that on balance they are seen as a successful way of raising capital and delivering better quality public services.

Three important efficiency factors of PPP:

- PPPs are long-term commercial partnerships between the public and private sectors. This definition of PPPs matters because it distinguishes PPPs from outsourcing arrangements and privatisations. Viewing PPPs as commercial partnerships, rather than as purely contractual relationships, has wide-ranging implications for how PPP programmes are designed and implemented.

- The benefits of PPPs are much broader than accessing private capital. PPPs can help governments overcome short-term fiscal constraints; but their long-term benefits should be the delivery of improved infrastructure services at lower cost. Getting the early design of PPPs right is critical to ensure that these long-term 'value for money' benefits are realised.

- PPPs can deliver significant benefits in terms of increased quality and quantity of infrastructure services, often at a lower overall cost compared to public sector provision. On the other hand, when PPPs fail, the financial, social and political costs can be very high. There are no short cuts to good project development; taking the time to get the early design of PPPs right is essential when there is so much at stake.

\section{Materials and methods}

Many lawyers treat PPP like any other contract made with a public body. But PPP is not just any other contract. PPP bring public and private sectors together in long term partnership for mutual benefit. PPP doesn't have a statutory definition. You can see one of them on the screen. PPPs are long-term contractual arrangements between the public and private sectors for the delivery of public services. The defining feature of PPPs, as against other forms of private participation in infrastructure, is that there is a significant degree of risk sharing between the two parties. Put simply, risk sharing means that both the government and the investors will suffer financially if the contract fails. The benefits of PPPs, discussed in more detail below, come about because both parties are incentivised to ensure that the contract is a success over the full project life. The degree of benefits largely depends on how well risks are allocated between the public and private sector and how strongly the incentives are built into the contract.

A PPP is a long-term contractual arrangement for the delivery of public services where there is a significant degree of risk sharing between the public and private sectors.

Generally speaking, PPP is broken dawn into 3 different kinds:

- Private ownership in otherwise state owned business

- PFI (Private Finance Initiative)

- Government services sold to wider private markets

PPP/PFI are thus associated with features such as VFM, risk allocation, joint working, control, the long term, assets and specific outcomes.

Among all the relationships involved in PPP/PFI I focus on three

- the relationship linking public and private partner together

- the relationship linking public entities with individuals, especially users

- the relationship linking PPP/PFI with individuals

The difference between PPPs and PFIs

The private finance initiative relates to a UK government initiative on PPPs. A PFI contract is a form of PPP where, in its most common form, the private sector designs, 
builds, finances and operates (DBFO) facilities based on 'output' specifications decided by the public sector.

Under a PFI contract, the public sector does not own the asset, but pays the PFI contractor a stream of committed revenue payments for the use of the facilities during the contract period.

Once the contract has expired, the ownership of the assets either remains with the private sector contractor or is returned to the public sector, as per the original terms of the contract.

The term PFI has also sometimes been used in a misleading manner to refer to all PPPs in the UK. It should actually refer only to those PPP contracts where the private sector performs the DBFO functions and in return receives a fixed payment stream from the government.

The PFI-type model has mainly been applied to social infrastructure projects such as schools and hospitals in the UK. Its applicability bears direct relevance to the UK government policy on these social infrastructure services being regarded as merit goods. There is a question as to the direct applicability of the PFI model to developing countries, stemming from two key issues: (i) the capacity of developing country governments to provide a regular payment stream to the PFI contractor; and (ii) the poor creditworthiness of some governments for private investors and therefore the higher cost of capital and concomitant impact on the value for money of the potential contract.

All 3 kinds of PPP have common features.

1. The private sector must genuinely assume risk

2. Value for money (vfM)

3. Collaboration, joint working and risk sharing

4. Provision of associated services of a specified quality

5. Long term

- Risk transfer: The key element of a PPP contract is the transfer of risk from the public to the private sector. The principle behind this risk transfer is that risk should be allocated to the party that can best manage it. Within the suite of PPP contracts, certain risks relating to the design, construction and operation of the infrastructure are transferred to the private sector, where it has a greater capacity (e.g. financial resources) and ability (e.g. skills and expertise) to mitigate the losses arising from the risks. Section 3.3 provides a detailed discussion on the types of risks and their allocation.

- Long-term contract: A PPP usually follows a 'whole-of-life' approach to the development of the infrastructure, thus requiring the contract to be long term in nature. A PPP is typically for a period of 10 to 20 years - although there are some PPPs that may be of a shorter duration of, say, three to five years.

- Partnership agreement: Key to this long-term contract between the public and private sectors is that it is viewed as a 'partnership', in that both parties have a mutual interest and a unified commitment. PPPs represent co-operation between the public and private sectors, drawing on the relative strengths of each party, in order to establish a complementary relationship between them.

Consist of different sets of contractual documents with many appendices. These documents organize the relationship between London Underground Ltd, a public body and tube lines, from one hand, and London Underground Ltd and Metronet, from the other hand. These relationships were the outcome of financial and political negotiations between the London authorities, the central government and market actors during the procurement process. So, i $m$ sure that formalization and hybridity are both needed to explain PPP/PFI but are not sufficient: formal certainty and maximizing calculation do not fully explain how discretion is used in terms of coordinating public, private and individual interests in PPP/PFI. It therefore highlights the structures which shape how discretion is used in 
PPP/PFI and how these structures narrow down and widen discretion in attempting to articulate concerns for autonomy, solidarity and trust in daily decisions.

\section{Results and discussion}

Now we'll discuss the key elements which are necessary to analyse the tensions that PPP actors face. PPP bring together public and private actors, state and market logics to provide public infrastructure and services to individual users who rely on them for their economic and social lives. But these relationships are characterized by 3 kinds of tensions.

1. Tension between public and private dimension

2. Tension between flexibility and stability

3. Tension between efficient allocation and fair distribution of benefits

Problems of coordination arise from hybridity. However the hybridity may also be positive as it brings private and public actors into cooperation, they may also facilitate (способствовать) the coordination of their respective interests in the long term. This may need the development of adequate accountability and regulatory techniques or standards to assess this coordination. So I can assert that the law needs to be supplemented by ethical framework.

The second tension is the long duration of relationship to which public and private partners commit themselves: ppp is usually signed for minimum period 20-30 years. Therefore changes are inevitable, because of new policy initiatives, legislative changes, which may have direct or indirect influence.

For example,

a)whenstatutory and regulatory standards (health or safety) are strengthened or if specific transparency requirements for ppp are brought into the statutes dealing with freedom of information.

b)the evolution of the political or financial situation.

The evidence of this is 2008 financial crisis and the 2010 change of government in the UK.

So the actors of PPP have to find a solution for changing circumstances. Contact law offers more or less appropriate exit solutions: it`s possible to change some treaty provisions, party develop solidarity and share risks. Ex: changes in the contract may require a new public procurement procedure.

PPP also challenge contact law when the changing circumstances are related to a change in conception of public interests: public authorities have the duty to continually serve the public good, which may change over time, especially over such long periods of 20-30 years. Ex: underground, hospitals, ets.

PPP usually entail sensitive projects such as hospitals, prisons, schools, transport. So the public and private actors are dealing with third parties, individuals (users), who are getting a benefit from the contract. In short, third parties are affected either positively or negatively. They need to adapt their expectation in light of the modalities in which a service is delivered. Three main categories of individuals: taxpayers, users, dissatisfied parties. These 3 categories of individuals have the impact of PPP on their interests. Taxpayers seek value for money (VFM) for the services delivered through PPP, users expect the service to be designed and implemented so their specific needs are met. Aggrieved parties want to have a picture of their entitlement (patient, prisoners).

In 2007 Department of health in UK approved a PPP contract for Peterborough and Stamford hospitals in order to bring its operation in to one single location. In 2010 financial difficulties have begun.

- hospital was delivering services without adequate payment 
- hospital have to seek alternative income sources from natural commissioning body and attract patients from neighbouring area. In doing so the hospital was depriving another hospital of its own patients an income streams.

This case is illustrated the interplay between a range of decisions taken by the PPP hospital and difficulty of appreciating the short and long term effects of a set of decisions or their geographic impact.

PPP is hybrid relying on a variety of legal and non-legal techniques, on contracts and organizations and public and private actors. Similarly, PPP seeks to address a range of financial, social or regulatory issuesfor instance, the long lasting lack of investment in public infrastructures such as LU or need for more rooms in prisons. They are used to provide a public service and fulfil a regulatory aim, in the sense of an activity valued by a community.

PPP regulatory space involves a series of relationships between public and private actors and third parties. These relationships are connected within that space according to ideas of autonomy, solidarity and trust, leading to non legal mechanisms of coordination to support the relationships between public and private actors and between PPP and the community of users.

Cooperation and competition bring market benefits (ex: resource allocation) and problems (ex: monopolies). The law is supposed to police competition problems without disturbing competition benefits. The law may to find an even more subtle balance regarding cooperation than competition. Formalisation of the relationships between PPP parties is needed (to regulate the balance between control. Cooperation and competition).

\section{Conclusions}

We could summary key lessons learned on best practice on infrastructure PPPs.

Lesson 1: PPPs should be designed with sustainability and value for money (VfM) considerations in mind.

1. Robust feasibility analysis is essential for successful PPPs. Many projects have failed where

governments and/or sponsors were over-optimistic about future revenues.

2. Proper due diligence is required when selecting a private sector sponsor. Weak sponsors

lacking relevant experience significantly increase the risk of project failure.

3. Even in cases where private finance is available, a PPP approach may not be the optimal solution if sustainability and value for money cannot be assured. Particular attention needs to be paid to the affordability of user fees.

Lesson 2: PPPs should be viewed as long-term commercial relationships between the public and private sectors, not one-off procurement exercises.

1. The public sector has an important ongoing role beyond the financing stage ('financial close') of a project to ensure that desired long-term outcomes are achieved.

2. Establishing a flexible PPP framework helps establish the 'rules of the game' under which the public and private sectors can interact successfully over the lifetime of a contract.

3 . The public sector needs staff with appropriate business skills and experience in order to manage the relationship with the private sector effectively.

Lesson 3: PPPs are inherently complex, costly and time-consuming to develop properly.

1. PPPs require high-level political support, especially during the project development stage to help overcome the typical obstacles that PPP projects encounter.

2. It is important to manage political expectations about the time it takes to design and execute a PPP project properly (the project development phase from concept to financial close typically takes from three to four years). 
3. Expert legal, financial and technical advice is expensive, but essential to ensure proper project design. At the same time, governments should build in-house capacity to manage third-party advisers effectively.

\section{References}

1. K. Abdul Rashid, Private Finance Initiative (PFI): Concept and method of procurement for construction projects with specific reference to Malaysia (2007)

2. A. Akintoye, C. Hardcastle, M. Beck, E. Chinyio, D. Asenova, Construction Management and Economics, 21, 461 (2003)

3. A. Anderson, Value for money drivers in the Private finance Initiative, Report Commissioned by the Treasury Taskforce (2000)

4. Assessing value for money: A guide to infrastructure Ontarios "s methodology (2007)

5. J. Broadbent, J. Gill, R. Laughlin, Auditing and Accountability Journal, 16 (3) (2003)

6. E. Cheung, A.P. Chan, S. Kajewski, Journal of Financial Management of Property and Construction, 14 (1), 7 (2009)

7. I. Demirag, M.Dubnick, M.I. Khadaroo, A framework for examining Accountability and Value for money in the UK"s Private Finance Initiative (2004)

8. T. Edge, Untested model for Malaysian companies, 75 (2006)

9. P. Edwards, J. Shoul, Accounting, Auditing \& Accountability Journal, 16 (3), 397 (2002)

10. L. English, UNSW Law journal, 29, 250 (2006)

11. L. English, J. Guthrie, Accounting, Auditing \& Accountability Journal, 16(3), 493 (2003)

12. A. Eversdijk, P.V Beek, W. Smits, 3rd International Public Procurement Conference Proceedings (2008)

13. D. Heald, Accounting, Auditing and Accountability Journal, 16 (3), 342 (2003)

14. H.M. Treasury, Value for money assessment guidance, Crown copyright (2006)

15. N. Pitt, N. Collins, A. Walls, The private finance initiative and value for money. Journal of property investment and finance, 24 (4), 363 (2006)

16. A.M. Yahya, PFI Insight \& Opportunities in Malaysia (2009)

17. Yseult Marique, Public private partnership and the law: regulation, institutions and community (2014) 